\title{
Ocorrência de Salmonella spp. em carcaças de frangos industrialmente processadas, procedentes de explorações industriais do Estado de São Paulo, Brasil
}

\author{
Occurrence of Salmonella spp. in broiler carcasses from slaughter plants of São Paulo, Brazil
}

\author{
Eliana Neire Castiglioni Tessari ${ }^{{ }^{*}}$ Ana Lucia Sicchiroli Paschoal Cardoso ${ }^{I}$ Ana Maria Iba Kanashiro ${ }^{\mathrm{I}}$ \\ Greice Filomena Zanatta Stoppa ${ }^{\mathrm{I}}$ Renato Luís Luciano ${ }^{\mathrm{I}}$ Antonio Guilherme Machado de Castro ${ }^{\mathrm{I}}$
}

\section{RESUMO}

A demanda de alimentos seguros aumentou no mercado. Além disso, a ausência de determinados microrganismos causadores de zoonoses em alimentos é uma exigência de regulamentos nacionais e internacionais. No entanto, mesmo com avanços tecnológicos, a carne de frango ainda é sujeita à contaminação bacteriana, especialmente por microorganismos do gênero Salmonella. Portanto, os objetivos deste trabalho foram: 1) pesquisar a ocorrência de Salmonella em carcaças de frango prontas para serem distribuídas no comércio e procedentes de explorações industriais do Estado de São Paulo e 2) classificar as amostras processadas quanto à presença ou à ausência de Salmonella em 25 gramas do produto. Para a realização do estudo, 116 amostras de carcaças de frango congeladas foram coletadas e analisadas, por meio do método convencional de cultivo, durante o período de julho de 2006 a junho de 2007. Deste total, duas amostras (1,7\%) apresentaram contaminação por Salmonella spp. e uma $(0,8 \%)$ por Salmonella Enteritidis, totalizando três amostras positivas (2,5\%). Apesar de os resultados terem demonstrado uma porcentagem de contaminação menor que a verificada em outras pesquisas, os resultados obtidos representam um problema para a saúde pública.

Palavras-chave: Salmonella, frangos, carcaças.

\section{ABSTRACT}

In the last years the demand for safe food has turned into an increasing necessity for market. Besides, the absence of any microorganism responsible for zoonosis is a requirement of national and international rules. However, even with technological development broiler meat is still susceptible to bacteria contamination, especially Salmonella. The aim of this research was to study the occurrence of Salmonella in broiler carcasses, from São Paulo slaughter plants ready to be distributed to the market. The research classified the samples according to presence or absence of Salmonella in $25 \mathrm{~g}$ of the product. One hundred and sixteen frozen broiler carcasses were collected and analyzed, using a conventional culture method, during one year (July 2006 - June 2007). A total of two (1.7\%) samples presented Salmonella spp and one (0.8\%) Salmonella Enteritidis, numbering three positive samples (2.5\%). Although this research showed a lower contamination rate comparing to other studies, the results are still a concern to public health.

Key words: Salmonella, broiler, carcass.

\section{INTRODUÇÃO}

As enfermidades transmitidas por alimentos (ETA) têm sido, nos últimos anos, motivo de discussões, em todo o mundo, sobre as estratégias que permitam o controle das ETAs e, conseqüentemente, a garantia da colocação de produtos inócuos no mercado consumidor (MATHEUS et al., 2003). O aumento de ETA verificado nos últimos anos, em muitos países, é influenciado por vários fatores, como, por exemplo, a intensificação da produção, que dificulta o controle das ETAs pelas autoridades de saúde pública. Outro fator é a criação intensiva dos animais de produção (MOTARJEMI \& KÄFERSTEIN, 1999). O rápido crescimento da indústria avícola, por exemplo, proporcionou uma fonte de proteína rapidamente disponibilizada e de custo reduzido, mas também aumentou a taxa de infecção das aves e conseqüentemente a contaminação das carcaças (SILVA, 1998; VIEIRA \& TEIXEIRA, 1997).

ICentro Avançado de Pesquisa Tecnológica do Agronegócio Avícola, Instituto Biológico. Rua Bezerra Paes, 2278, 13690-000, Descalvado, SP, Brasil. E-mail: etessari@biologico.sp.gov.br. *Autor para correspondência. 
Entre os patógenos veiculados na avicultura, destacam-se os do gênero Salmonella e a importância da disseminação deste patógeno vem sendo amplamente estudada na cadeia produtiva das aves (SILVA \& DUARTE, 2002). Durante o processamento da carne, pode ocorrer a contaminação do próprio ambiente e dos manipuladores e a contaminação cruzada de outras aves contaminadas. A ausência de determinados microrganismos causadores de zoonoses em produtos de origem animal específicos é uma exigência de regulamentos nacionais e internacionais (SILVA, 1998). Em vista disso, o Ministério da Agricultura, da Pecuária e do Abastecimento estabeleceu um plano pioneiro em nosso país, o chamado "Programa de redução de patógenos - Monitoramento microbiológico e controle de Salmonella spp. em carcaças de frangos e perus”, com o objetivo de realizar um monitoramento constante do nível de contaminação por este patógeno em estabelecimentos de abate de aves. Esse plano foi estabelecido por meio da Instrução Normativa $n^{\circ} .70$ (BRASIL, 2003), que confere um controle minucioso sobre o processo de abate e atende as exigências de segurança do alimento baseado nos princípios de Boas Práticas de Fabricação (BPF), no Procedimento Padrão de Higiene Operacional (PPHO) e na Análise de Perigos e Pontos Críticos de Controle (APPCC).

A Salmonella tem sido uma preocupação, ao longo dos anos, na indústria de produtos avícolas. A partir da crescente ênfase na segurança de produtos cárneos que chegam ao consumidor, tem-se estimulado a identificação de meios para reduzir ou eliminar Salmonella spp. antes do abate, uma vez que a redução das taxas de infecção pré-abate resulta em aumento na segurança dos produtos avícolas (FUNK et al., 2001). As salmonelas estão amplamente difundidas na natureza e são capazes de infectar o homem e os animais. As aves acometidas por salmonelas paratíficas podem desenvolver a doença clinicamente ou de forma assintomática, albergando esses agentes e tornandose fonte em potencial da bactéria para seres humanos (BARROW, 1993). Os casos de infecções alimentares causadas por Salmonella aumentaram a partir da década de 80. RODRIGUE et al. (1990) atribuíram esse aumento ao consumo de ovos e subprodutos contaminados por Salmonella Enteritidis. Todavia, a presença de Salmonella em carcaças de frangos não pode ser ignorada (SAKAI \& CHALERMCHAIKIT, 1996; WARD \& THRELFALL, 1997). Em vista do exposto, o presente estudo foi realizado com o objetivo de investigar a presença de Salmonella em carcaças de frangos, procedentes de explorações industriais do Estado de São Paulo.

\section{MATERIAL E MÉTODOS}

Entre o período de julho de 2006 e junho de 2007, pesquisou-se a presença de Salmonella spp. em 116 carcaças de frango obtidas de abatedouros do Estado de São Paulo. A metodologia empregada foi a recomendada pela a American Public Health Association (FLOWERS et al., 1992), com modificações pertinentes relacionadas à substituição do caldo de pré-enriquecimento por água peptonada $1 \%$ tamponada.

As amostras em suas embalagens originais foram descongeladas “overnight” em geladeira com temperatura média de $4^{\circ} \mathrm{C}$. Amostras de 25 gramas foram adicionadas a $225 \mathrm{~mL}$ de água peptonada tamponada $1 \%$, homogeneizadas e incubadas a $41^{\circ} \mathrm{C}( \pm 2)$ por um período de 18 a 24 horas. Posteriormente, alíquotas de $1 \mathrm{~mL}$ das amostras foram transferidas para $10 \mathrm{~mL}$ de caldo tetrationato-verde brilhante $\left(\right.$ Merck $\left.^{\circledR}\right)$ e $10 \mathrm{~mL}$ para caldo Selenito Broth $\left(\right.$ Merck $\left.^{\circledR}\right)$ e incubadas a $41^{\circ} \mathrm{C}( \pm 2)$ por um período de 24 horas. Após este período, realizouse plaqueamento em dois diferentes meios de cultura: Xilose-Lisina-Tergitol 4 (XLT-4 Merck ${ }^{\circledR}$ ) e Mac-Conkey $\left(\right.$ Merck $^{\circledR}$ ), sendo incubados a $37^{\circ} \mathrm{C} / 24$ horas. As colônias suspeitas foram submetidas a uma triagem por meio de testes bioquímicos utilizando-se ágar lisina descarboxilase (LIA), ágar tríplice açúcar ferro (TSI), caldo uréia e meio SIM (SIM Medium). As colônias que apresentaram perfil bioquímico compatível com o gênero Salmonella foram inoculadas na série bioquímica complementar. Nas amostras compatíveis, realizou-se a sorotipificação utilizando-se antisoros específicos (BIO-RAD ${ }^{\circledR}$ ).

\section{RESULTADOS E DISCUSSÃO}

Do total de 116 amostras analisadas, duas (1,7\%) apresentaram contaminação por Salmonella spp. e uma $(0,8 \%)$ por Salmonella Enteritidis, totalizando três (2,5\%) amostras positivas. Resultados com valores superiores foram encontrados por ALMEIDA et al. (2000), sendo que, das 15 amostras de carcaças de frango congeladas analisadas, em sete foi detectada a presença de bactérias do gênero Salmonella e, em 15 amostras de carcaças de frango resfriadas, observaramse 13 amostras positivas para este patógeno. FORSTER \& MEAD (1976) verificaram que salmonelas em carne de frango são destruídas mais rapidamente em temperaturas entre $-2 \mathrm{e}-5^{\circ} \mathrm{C}$, visto que o congelamento da carcaça tende a reduzir ou prejudicar a sobrevivência de enterobactérias.

Pesquisas referentes à Salmonella em carcaças de frango, realizadas nas décadas de 70 e 80 
no Brasil, detectaram valores muito superiores aos encontrados no presente trabalho (ÁVILA et al., 1974). Nestes estudos observou-se que o sorovar Enteritidis não era muito freqüente. No entanto, a partir de 1993, verificou-se um aumento na freqüência de isolamento de Salmonella Enteritidis (IRINO et al., 1996). De acordo com ALTEKRUSE et al. (2006), houve um aumento significativo no isolamento de Salmonella nos Estados Unidos, entre os anos de 2000 e 2005, predominando o sorovar Enteritidis.

A ocorrência de Salmonella spp. em carne de aves tem sido constatada por diferentes pesquisadores. REITER et al. (2007) observaram a presença de Salmonella em 33 das 615 amostras analisadas por meio do método de ELISA (enzymelinked immunosorbent assay) e 12 amostras positivas em 47 analisadas por meio da metodologia de cultura tradicional. CARVALHO \& CORTEZ (2005) relataram a presença de Salmonella spp. em 33 amostras de um total de 165 pesquisadas e REZENDE et al. (2005) observaram uma freqüência de achados positivos para Salmonella spp. em 19 de 96 amostras de carcaças de frango analisadas, sendo que das amostras positivas 12 foram identificadas como sorovar Enteritidis. Já SILVA et al. (2004) observaram que, das 30 amostras de carcaças de frango pesquisadas, 13 apresentaram a presença de Salmonella spp.. TESSARI et al. (2003) relataram a presença deste microorganismo em 13 das 68 amostras analisadas e ALMEIDA FILHO et al. (2003) constataram 18 amostras contaminadas em 40 analisadas. FUZIHARA et al. (2000) obtiveram positividade para Salmonella em $42 \%$ das amostras de carcaças de frango processadas industrialmente, sendo que $30 \%$ dos sorovares foram identificados como Salmonella Enteritidis.

Os surtos de salmonelose humana foram relatados pela primeira vez por Gaffky em 1880 (CORRÊA \& CORRÊA, 1992), sendo que o sistema de produção e abate de frangos tende a favorecer a presença de Salmonella no produto final (BERCHIERI et al. 1987, 1989). Nesses produtos, a presença desse microorganismo significa risco à saúde do consumidor, caso o produto não seja adequadamente conservado e preparado. Portanto, é fundamental que haja um canal de comunicação entre o fomento e a indústria, com medidas sanitárias e tecnológicas rigorosas, que efetivamente tenham influência sobre a redução da prevalência de Salmonella no produto (BERSOT, 2006).

\section{CONCLUSÃO}

Os resultados dessa pesquisa, do ponto de vista de vigilância sanitária, indicam a importância da implantação de programas específicos para o controle de Salmonella, visto que a maioria dos sorotipos são potencialmente patogênicos ao homem e a ocorrência deste patógeno em amostras é de interesse da saúde pública. A porcentagem de amostras positivas, apesar de pequena, representa risco potencial para a saúde da população consumidora.

\section{REFERÊNCIAS}

ALMEIDA, I.C. et al. Isolamento e identificação de salmonela em carcaças de frango congelados e frescais, através de método rápido. Higiene Alimentar, v.14, n.70, p.59-62, 2000.

ALMEIDA FILHO, E.S. et al. Pesquisa de Salmonella spp em carcaças de frango (Gallus gallus), comercializadas em feira livre ou em supermercado no município de Cuiabá, MT, Brasil. Higiene Alimentar, v.17, n.110, p.74-79, 2003.

ÁVILA, F.A. et al. Salmonella em carcaças de aves manipuladas nos abatedouros de Belo Horizonte. Arquivos da Escola Veterinária da Universidade Federal de Minas Gerais, v.26, p.211-214, 1974.

ALTEKRUSE, S.F. et al. Salmonella Enteritidis in broiler chickens, United States, 2000-2005. Emerging Infectious Diseases, v.2, n.12, p.1848-1852, 2006.

BARROW, P.A. Salmonella - present, past and future. Avian Pathology, v.22, p.651-669, 1993.

BERCHIERI JR., A. et al. Salmonella em abatedouro avícola. Ars Veterinária, v.3, n.1, p.81-87, 1987.

BERCHIERI JR., A. et al. Farinha de carne como fonte de Salmonella em granja avícola. Pesquisa Veterinária Brasileira, v.9, p.9-12, 1989.

BERSOT, L.S. Salmonella no Brasil: Sua importância no abate das aves. In: SIMPÓSIO DE SANIDADE AVÍCOLA DA UFSM, 5., 2006. Santa Maria, RS, Brasil. Anais... Santa Maria: UFSM, 2006. p.90-94.

BRASIL, Ministério da Agricultura e Abastecimento. Instrução Normativa $\mathrm{n}^{\circ} 70$, de 06 de outubro de 2003. Programa de Redução de Patógenos - Monitoramento Microbiológico e Controle de Salmonella sp. em Carcaças de Frangos e Perus, 2003. Diário Oficial da União de 10/10/2003, seção 1, p.9. Capturado em 25 de março de 2008. On line. Disponível na Internet: http://extranet.agricultura.gov.br/sislegs-consulta/ consultarLegislacao.DO?operacao=vi...

CARVALHO, A.C.F.B.; CORTEZ, A.L.L. Salmonella sp. em carcaças, carne mecanicamente separada, lingüiças e cortes comerciais de frango. Ciência Rural, v.35, n.6, p.14651468, 2005.

CORRÊA, W.M.; CORRÊA, C.M. Paratifos em geral. In: Enfermidades infecciosas dos mamíferos domésticos. 2.ed. Rio de Janeiro: MEDSI, 1992.

FLOWERS, R.S. et al. Salmonella. In: VANDERZANT, C.; SPLITTSTOESSER, D.F. Compendium of methods for 
microbiological examinations of foods. 3.ed. Washington: American Public Health Association, 1992. p.371-422.

FORSTER, R.D.; MEAD, G.C. Effect of temperature and added polyphosphate on the survival of salmonellae in poultry meat during cold storage. Journal of Applied Bacteriology, v.41, p.504-510, 1976.

FUNK, J.A. et al. Longitudinal study of Salmonella enterica in growing pigs reared in multiple-site swine production systems. Veterinary Microbiology, n.83, p.45-60, 2001.

FUZIHARA, T.O. et al. Prevalence and dissemination of Salmonella serotypes along the slaughtering process in Brazilian small poultry slaughterhouses. Journal of Food Protection, v.63, p.1749-1753, 2000.

IRINO, K. et al. Progression of Salmonella Enteritidis phage type 4 strains in São Paulo state, Brazil. Revista do Instituto de Medicina Tropical de São Paulo, v.12, p.193-196, 1996.

MATHEUS, D.P. et al. Ocorrência de Salmonella spp. em carne de frango comercializada no município de Bauru, SP, Brasil. Revista do Instituto Adolfo Lutz, v.62, n.2, p.111-115, 2003.

MOTARJEMI, Y.; KÄFERSTEIN, F. Food safety, hazard analysis and critical control point and the increase in foodborne disease: a paradox? Food Control, v.10, p.325-333, 1999.

REZENDE, C.S.M. et al. Sorovares de Salmonella isolados de carcaças de frangos de corte abatidos no estado de Goiás, e perfil de resistência a antimicrobianos. Revista Portuguesa de Ciências Veterinárias, v.100, n.555-556, p.199-203, 2005.
REITER, M.G.R. et al. Prevalence of Salmonella in a poultry slaughterhouse. Journal of Food Protection, v.70, n.7, p.1723-1725, 2007.

RODRIGUE, D.C. et al. International increase in Salmonella enteritidis: a new pandemic? Epidemiology and Infection, v.105, p.21-27, 1990

SAKAI, T.; CHALERMCHAIKIT, T. The major sources of Salmonella enteritidis in Thailand. International Journal of Food Microbiology, v.31, p.173-180, 1996.

SILVA, E.N. Salmonella Enteritidis em aves e saúde pública. Higiene Alimentar, v.9, p.9-12, 1998.

SILVA, E.N.; DUARTE, A. Salmonella Enteritidis em aves: Retrospectiva no Brasil. Revista Brasileira de Ciências Avícola, v.4, n.2, p.85-100, 2002.

SILVA, M.C.D. et al. Salmonella spp. em ovos e carcaças de frangos "in natura” comercializados em Maceió, AL. Higiene Alimentar, v.18, n.121, p.80-84, 2004.

TESSARI, E.N.C. et al. Prevalência de Salmonella Enteritidis em carcaças de frango industrialmente processadas. Higiene Alimentar, v.17, n.107, p.52-55, 2003.

VIEIRA, C.R.N.; TEIXEIRA, C.G. Condições higiênicosanitárias de carcaças de frango resfriadas comercializadas em Poços de Caldas, MG. Higiene Alimentar, v.11, p.36-40, 1997.

WARD, L.R.; THRELFALL E.J. Human salmonellosis in England and Wales - current situation. In: INTERNATIONAL SYMPOSIUM SALMONELLA AND SALMONELLOSIS. 1997. Ploufragan. França. Proceedings... Ploufragan: ISPAIA, 1997. p.547-549. 